\title{
Electronic Device Use and Fine Motor Dexterity \& Handwriting: A Pilot Study of South African Grade 2 Children
}

\author{
Monique M. Keller ${ }^{1} \&$ Pragashnie Govender ${ }^{2}$ \\ ${ }^{1}$ Department of Physiotherapy, School of Therapeutic Sciences, Faculty of Health Sciences, University of \\ Witwatersrand, South Africa \\ ${ }^{2}$ Discipline of Occupational Therapy, School of Health Sciences, University of KwaZulu-Natal, South Africa \\ Correspondence: Monique M. Keller, School of Therapeutic Sciences, University of the Witwatersrand, Gauteng, \\ South Africa. Tel: 27-84-402-9493. E-mail: monique.keller@wits.ac.za
}

Received: November 30, 2018 Accepted: December 18, 2018 Online Published: March 15, 2019

doi:10.5539/gjhs.v11n4p76

\author{
URL: https://doi.org/10.5539/gjhs.v11n4p76
}

\begin{abstract}
Electronic media is at an all-time high in contemporary society with the developmental impact of electronic use still mostly unknown. This study aimed at determining the association between electronic device use and the impact on handwriting and dexterity in grade two children. Thirty four children aged between 7.2 to 8.1 years participated in a pilot study. A parental self-administered questionnaire was used to determine type and frequency of electronic usage, the Minnesota Handwriting Assessment measured six handwriting domains and the Nine-Hole-Peg-Test measured dexterity. Statistically significant correlations were computed for device use and handwriting score $(r=0.110)$ and device use and non-dominant hand dexterity $(r=0.137)$. Male children's handwriting speed was superior $(\mathrm{p}<0.015)$ and female children's form of handwriting emerged as superior $(\mathrm{p}<$ 0.005). This study provides data on the potential impact of frequent device use on the overall fine motor development.
\end{abstract}

Keywords: electronic devices, fine motor performance, handwriting

\section{Introduction}

The human hand is the most developed organ for prehensile use among all living creatures (Mennen \& van Velze, 2008) and among children between the ages of seven and eight years, this highly developed prehensile organ develops through fine motor activities such as handwriting. There is however a lack of empirical evidence on children who do not master this stage of handwriting development and who utilise electronic devices more frequently.

When mobile devices and gaming equipment enter into a household, it is frequently used by younger children. Children, many between two and six years of age, have smaller hands which often do not fit devices that are designed for an older population (Bryant, Akerman, \& Drell, 2010). Bryant et al. (2010) in their study considered the relationship between commonly used devices and the fine motor skills required for usage and reported that the Nintendo DS and other handheld devices require fine motor skills for usage while the Nintendo Wii requires primary gross motor skills. Certain console video games require hand use during play with the large controllers that incorporate different hand functions than normal recreational activities, for example, cutting, drawing and play with play-dough, which incorporates more fine motor and intrinsic hand function (Bryant et al., 2010).

The modern era is undoubtedly characterised by an increase in availability and use of electronic devices, especially mobile devices such as cellular phones and tablet computers (Common Sense Media, 2013). The impact of mobile devices on child and adolescent development however remains mostly unknown. South Africa (SA), in particular leads the mobile technology growth on the African continent, where SA residents have been viewed as the highest mobile technology users with $72 \%$ of youth and adolescents between 15-24 years of age owning a cellular phone (UNICEF, 2012) The increase in use of cellular phones and electronic media is of concern, moreover on the unknown impact on the development of children (Wartella \& Jennings, 2000). Electronic device use frequency for the purpose of the study will thus be defined as time (minutes) per day of the week and total time per week spent on each accessible electronic device used in home and school environments.

Children are increasingly being entertained by electronic devices and the media. This is supported by market 
research conducted in SA in older children (Wike \& Oates, 2014) and in seven to eight year olds in the USA (Common Sense Media, 2013). Straker et al. (2008) voiced concern over promoting the use of electronic devices such as tablet computers, which are being incorporated as a learning aid in some elementary school environments, without being aware of the physical impact on children. Additionally, frequent electronic device use is suggested by Bryant et al. (2010) as altering recreational activities.

Handwriting determines the success, self-esteem and communication of children in their school career with adequate writing skills being imperative for children to be able to "express their thoughts, feelings and ideas for both themselves and the intended audience" (KwaZulu Natal Department of Education, 2006). The importance of handwriting can also be seen in how elementary schoolchildren's handwriting is viewed by their teachers and peers as a reflection of their capabilities and intelligence (Connelly, Gee, \& Walsh, 2007). Early success in handwriting is thus imperative for children's future academic success and experience, because difficulties often persist well into their formal education (Naidoo, Engelbrecht, Lewis, \& Kekana, 2009). The correct handwriting instruction is only one external factor that influences handwriting at the foundation phase schooling level, with other factors including but not limited to; writing instruments, material used, sufficient time and the quality of handwriting practice undertaken.

The increase in the use of modern technology has led to the inquiry of the importance of handwriting instruction in the twenty first century (Hanover Research Report, 2012). Instruction in a school day currently still focusses on fine motor dexterity and handwriting development for children in grade zero (turning five years of age) to grade three (up to nine years of age). The time spent on fine motor dexterity and handwriting instruction can amount to more than $50 \%$ of a school day, where $85 \%$ is spent on handwriting instruction (van Hartingsveldt, de Groot, Arrts, \& Nijhuis-van der Staden, 2011; Tseng \& Chow, 2000).

It is important to remember that handwriting is not an automatic developmental process, but a skill that requires correct instruction and sufficient practice. If the handwriting of a child is not fluent and automatic in nature, the higher cognitive writing processes can be negatively challenged (Amundson, 2005). It is thus not only important for children to display fluent handwriting, but imperative for cognitive development.

Certain handwriting problems have its origin in the early foundation years of childhood development (Feder \& Majnemer, 2007). For a child to display fluent age appropriate handwriting, a complex interaction of various internal and external factors needs to be considered in its instruction (Feder \& Majnemer, 2007). Adequate fine motor dexterity development is a crucial prerequisite for fluent handwriting performance at an appropriate speed (Feder \& Majnemer, 2007; Henderson \& Pehoski, 2006).

The authors' speculation was that electronic device use is impacting on child development, more specifically handwriting and dexterity. This study therefore sought to determine the association between electronic device use and handwriting and dexterity in a cohort of grade two children in SA. As a first of its kind research, in the form of a pilot study, no conclusive correlation but an association was sought, so as to provide a foundation for future empirical research. The primary null hypothesis therefore stated that no statistical significant association and no gender differentials will be determined between electronic device use on fine motor dexterity and handwriting domains in grade two male and female scholars.

\section{Method}

\subsection{Design and Sampling}

This pilot study with a correlational study design was located in the East Rand of the province of Gauteng in South Africa. Purposive sampling was used in the selection of children from middle class independent schools. This was to ensure that a sample population that potentially use more electronic devices, based on the socio-economic demographics of these households were accessed (Zarghom, Di Fonzo, \& Leung, 2013). A sample size of 384 for large populations is sufficient to ensure approximately $5 \%$ error at a $95 \%$ confidence level (Chetty \& Bhagwanjee, 1990). On the basis of selecting a sample of $10 \%$ for the pilot study, 77 grade two children were randomly selected for participation, with 34 parents/primary caregivers providing consent. Children had to be between seven and eight years of age and in grade two. Children with any pre-existing diagnoses (attention deficit/hyperactivity disorder (ADD/ADHD), developmental co-ordination disorder (DCD)), preterm children; children with major physical disabilities, genetic disorders; prenatal exposure to alcohol; children with a history of head trauma and infections; psychiatric conditions such as autism and depression; children who had or were receiving occupational therapy intervention or remediation for handwriting or fine dexterity problems and children who were repeating a grade, were excluded. Consent was obtained from 34 parents or primary caregivers of children who met the inclusion criteria. The gender distribution was $23.5 \%$ males and $76.5 \%$ females. Children in this study had a mean 
age of 93.2 months (7.8 years), ranging from 86 months (7.2 years) to 97 months (8.1 years). Handedness among the children indicated $11.8 \%$ with left hand dominance and $88.2 \%$ with right hand dominance.

\subsection{Instruments}

The Minnesota Handwriting Assessment (MHA) (Reisman, 1999) was used to assess the children's handwriting performance in six domains (speed, spacing, legibility, form, alignment and size) with additional observational faults observed during handwriting performance. Children were instructed to copy the following words: "The brown jumped lazy fox quick dogs over", on the provided solid lines (baselines) on the lower half of the test sheet, making their letters the same size as the sample and using their best handwriting. Scoring of the written letters was according to standardised scoring instructions for each of the domains. In addition to the five qualitative categories, the subjects received a rate score, earning one point for each letter completed within the first two and half minutes of the assessment. The five qualitative scores combined with the rate score, for 34 letters, can earn up to six points per letter written. A maximum total score of 204 was possible (Fuentes, Mostofsky, \& Bastian, 2009). The administration of the test took two and a half minutes per class and the scoring three to seven minutes per subject. The reliability of the MHA had been improved by the use of the same writing utensils, chair and desks, similar external environment in one class room and during the same time period in the year and day (break-time). The same verbal instructions were given to all the participants before the commencement of the test. Reasons for assessing handwriting performance with the MHA includes; ease of administration, good inter and intrarater reliability, the strong construct validity, extra handwriting observational assessments and its usefulness as a successful predictor of good and poor handwriting among grade two children (Reisman, 1999). Nine-Hole Peg Test (NHPT) (Smith \& Hong, 2000) assessed fine motor dexterity. The NHPT consist of nine plastic pegs $(0.6 \mathrm{~cm}$ in diameter) with a moulded dish next to the pegboard $(31 \times 26 \times 4 \mathrm{~cm})$ with holes where the pegs must be inserted. Standard instructions were given to children prior and during testing where they were asked to put the nine pegs in the pegboard holes, take them out and place them back in the moulded container as fast as possible. The time in seconds was measured with a stopwatch that comes standard with the test. The stopwatch measures time to the closest millisecond. The NHPT was selected for this research study, because of the simple, efficient, short administration time ( 3 minutes), the low cost and the high test-retest reliability coefficients for right and left hands measured at 0.95 and 0.92 , respectively. The NHPT further correlates with the Purdue Pegboard at -0.74 to -0.75 (Wang et al., 2011). The NHPT has been found to be an effective screening tool for fine motor dexterity in school-age children and comparisons were based on Smith \& Hong's (2000) study. A self-administered parental/primary caregiver questionnaire determined demographic details (parents and children), type and frequency of grade two children's electronic device use.

\subsection{Data Analysis}

Data was captured in an Excel spreadsheet. The IBM SPSS version 22 was used to analyse the data. A p value of $<0.05$ was considered as statistically significant. Non parametric tests were computed given that continuous measures were not normally distributed. Mann Whitney tests were used to compare medians between two groups, Fischer's exact tests were used to compare proportions between two groups, and Spearman's rank correlation was used to compute correlation coefficients between two variables.

\subsection{Ethics}

Data collection commenced after ethical clearance had been obtained from a Biomedical Research Ethical Committee (BE292/14); the educational ministry of the relevant province, principals of the elementary department from each school, prior to school entry. Respect for persons was maintained by obtaining informed consent from the parents/ primary caregivers and written assent from the children prior to testing.

\section{Results}

Cellular phones were most frequently used (94.1\%), with the touch screen cellular phone (smartphone) utilised more than manual phones (Table 1). 
Table 1. Electronic Devices used by children in this study $(n=34)$

\begin{tabular}{llll}
\hline \multirow{2}{*}{ Cellular phone } & Touch screen & $76.5 \%$ & $94.1 \%$ \\
& Manual typing & $17.7 \%$ & $88.2 \%$ \\
\multirow{2}{*}{ Tablet } & Standard size & $52.9 \%$ & $35.3 \%$ \\
& Mini & $41.2 \%$ & $76.5 \%$ \\
\hline \multirow{2}{*}{ Video Games } & Console & $35.3 \%$ & $73.5 \%$ \\
\hline \multirow{2}{*}{ Computer } & Handheld & $29.4 \%$ & $11.8 \%$ \\
\hline Other & Desktop & $44.1 \%$ & $11.8 \%$ \\
\hline
\end{tabular}

Use of electronic devices over the weekends exceeded the amount of time in the weekdays, by more than double as can be seen in Figure 1.

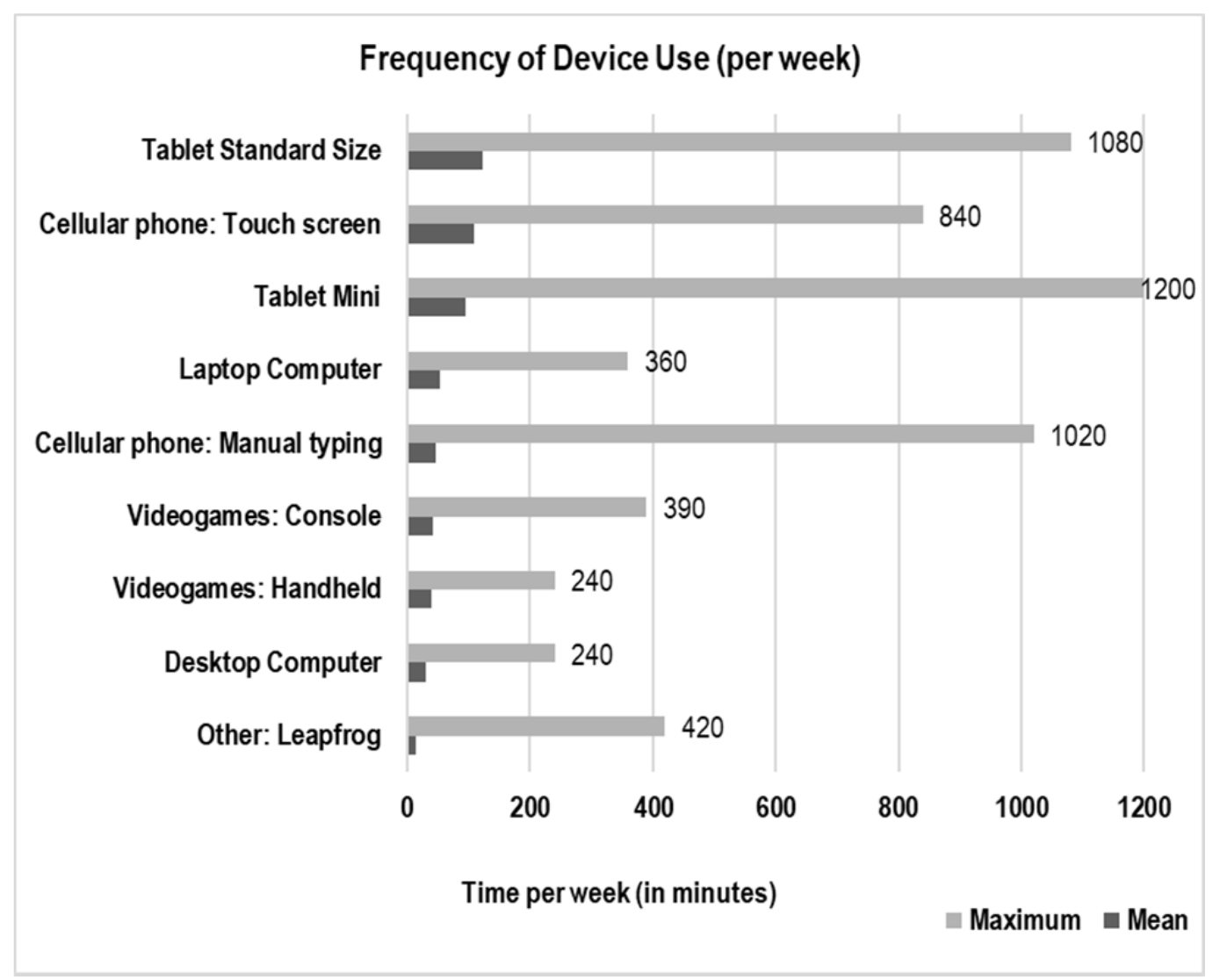

Figure 1. Frequency of Electronic Device Usage (per week in minutes)

Figure 2 represents the average/mean and maximum weekly usage per device type with mean and maximum scores for the nine different devices. 


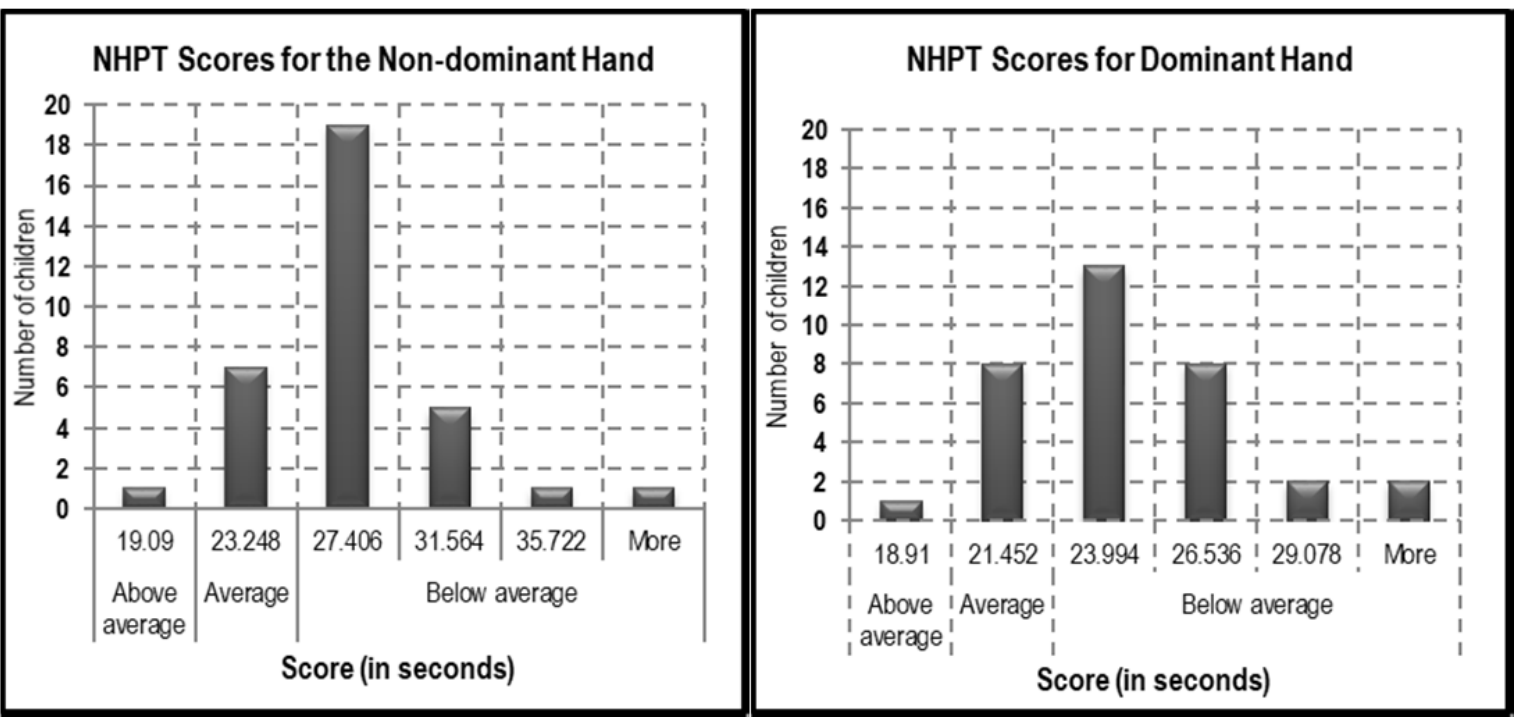

Figure 2. Average time (in seconds) to complete the NHPT for the dominant and non-dominant hand

The NHPT was used to measure dexterity for the dominant and non- dominant hand in the children (Figure 2). The completion time was normally distributed throughout the sample of 34 participants, with a mean score of 23.22 seconds, ranging from 18.91 to 31.62 seconds. Gender differentials for the NHPT results on the dominant hand revealed female children's scores with a mean of 22.98 seconds and male children's mean of 24.00 seconds. Table 2 highlights the handwriting results of the female and male children in this study.

Table 2. Average MHA results for male and female children $(n=34)$

\begin{tabular}{|c|c|c|c|c|c|c|}
\hline $\begin{array}{l}\text { MHA } \\
\text { Categories }\end{array}$ & $\begin{array}{l}\text { Total } \\
\text { participants }\end{array}$ & $\begin{array}{l}\text { Scoring category } \\
\text { (Performance) }\end{array}$ & Female & $\begin{array}{l}\text { Scoring category } \\
\text { (Performance) }\end{array}$ & Male & $\begin{array}{l}\text { Scoring category } \\
\text { (Performance) }\end{array}$ \\
\hline $\begin{array}{l}\text { Handwriting } \\
\text { Total }\end{array}$ & 183.7 & Like peers & 181.7 & $\begin{array}{l}\text { Somewhat below } \\
\text { peers }\end{array}$ & 190.1 & Like peers \\
\hline Legibility & 33.7 & Like peers & 33.7 & Like peers & 33.6 & Like peers \\
\hline Form & 32.3 & Like peers & 33.5 & Like peers & 28.4 & $\begin{array}{l}\text { Somewhat below } \\
\text { peers }\end{array}$ \\
\hline Alignment & 32.2 & Like peers & 32.6 & Like peers & 30.6 & Like peers \\
\hline Size & 23.8 & $\begin{array}{l}\text { Somewhat below } \\
\text { peers }\end{array}$ & 21.5 & $\begin{array}{l}\text { Somewhat below } \\
\text { peers }\end{array}$ & 30.9 & Like peers \\
\hline Spacing & 32.2 & Like peers & 32.5 & Like peers & 31.3 & $\begin{array}{l}\text { Somewhat below } \\
\text { peers }\end{array}$ \\
\hline Rate/Speed & 26.3 & $\begin{array}{l}\text { Somewhat below } \\
\text { peers }\end{array}$ & 24.5 & $\begin{array}{l}\text { Somewhat below } \\
\text { peers }\end{array}$ & 32.1 & Like peers \\
\hline
\end{tabular}

A total of 16 children presented with an immature pencil grip. The frequent adjustment of the pencil grip was observed in four children. Weak trunk stability was observed in seven children and one of the children had a sitting balance fault. The type of electronic devices used and the gender differentials revealed no statistical significance, for the standard tablet $(\mathrm{p}<1)$, mini tablet $(\mathrm{p}<1)$, desktop computer $(\mathrm{p}<1)$, laptop computer $(\mathrm{p}<0.257)$, console video games $(p<0.228)$, touch screen cellular phone $(p<0.355)$ and the manual type cellular phone $(\mathrm{p}<0.609)$. Significance was established for handheld video game use $(\mathrm{p}<0.001)$, where the use by male children was greater than the female children. No significant difference in the total electronic device use averages of male and females $(\mathrm{p}<0.413)$ were established. Gender differentials in the fine motor dexterity ability of the dominant and non-dominant hands revealed no significant difference, when comparing the medians of male and female children. 
No statistical significance was noted when comparing gender differences against dexterity of the dominant ( $\mathrm{p}<$ $0.647)$ and non-dominant hands $(\mathrm{p}<0.485)$.

A mean total handwriting score of 190.1 for the males and a total of 181.7 for the females out of a possible 204 points possible were obtained (Table 2). The male children thus out-performed the female children in the total handwriting assessment. The total handwriting score revealed no significant difference $(p<0.152)$. Correlations between the dexterity and handwriting average scores were performed. The children's dexterity and handwriting for the dominant hand, showed a significant but weak negative correlation for females with $(r=-0.465)$. It is important to note the slower time in the NHPT, the faster the dexterity of the child. In this regard, the slower the dexterity of the females dominant hand (writing hand) the lower the handwriting scores. The less time taken in the NHPT results in more advance dexterity and thus correlates with improved handwriting. In the non-dominant hand, significant but weak negative correlations exists for both males $(r=-0.563)$ and females $(r=-0.492)$. The handwriting sub-categories were analysed for gender differentials and revealed the following results. A high significance was established for the speed/rate and form of handwriting between the medians of male and females. The male children scoring higher than females for rate of handwriting $(\mathrm{p}<0.015)$ and females scoring higher for form of handwriting than males with $(\mathrm{p}<0.005)$ and here the null hypothesis was rejected, being no statistical significant correlation will be determined between the rate and form handwriting domains between female and male grade two children.

In the other categories of handwriting the males outscored the females in total handwriting score $(\mathrm{p}<0.152)$ and size of handwriting $(\mathrm{p}<0.058)$. The females achieved higher scores in legibility $(\mathrm{p}<1)$, alignment $(\mathrm{p}<0.141)$, and spacing $(\mathrm{p}<0.327)$ of handwriting. Correlations for gender differentials between the handwriting category scores and fine motor dexterity for the dominant and non-dominant hand revealed some important correlations for the male children, but not statistically significant due to the small sample size. In the female children handwriting size was negatively correlated with the dexterity $(r=-0.626)$. No correlation was established between the fine motor dexterity in the dominant hand compared to the total electronic device usage per week $(\mathrm{p}<0.974)$.

Correlations between the total electronic device use and fine motor dexterity for the non-dominant hand showed a very weak positive correlation $(\mathrm{r}=0.137)$. An increase in electronic device use thus leads to longer time taken to complete the NHPT with poorer dexterity. The correlations between the total electronic device use and handwriting total score resulted in a weak positive correlation of $(r=0.110)$. Correlations between the total electronic device use and the sub-categories of handwriting revealed a weak positive correlation for legibility $(\mathrm{r}=$ $0.105)$, a weak positive correlation ( $\mathrm{r}=0.141)$ for alignment, a weak positive correlation for the rate/speed scores with $(\mathrm{r}=0.214)$ with a weak negative correlation $(\mathrm{r}=-0.141)$ for form of handwriting. No statistical significant correlations were measured when correlated to the MHA total score; for the pencil grip fault $(p<0.798)$, the weak trunk stability $(\mathrm{p}<0.151)$, poor sitting balance $(\mathrm{p}<0.118)$ and frequently adjustment of the pencil grip $(\mathrm{p}<0.925)$.

\section{Discussion}

This is the first study of its kind in SA. Handwriting remains the predominant task in the first three grades of the elementary school programme and amounts to more than fifty percent of time a day spent on handwriting and fine motor dexterity instruction in the classroom (Tseng \& Majnemer, 2007). In this study, devices were used for approximately five hours on a weekend on average. In a school week, children's time is devoted to formal education, handwriting instruction and extramural activities and it is over the weekends where the children have more time to experiment, develop through play and explore the environment. The most frequent devices used by both male and female children included touch screen (smartphone) cellular phones, and tablet computers. This is not surprising, as, according to Wike \& Oates (2014), 91\% of South African's own a cellular phone, with 33\% owning smart phones.

Videogame use was classified under the fourth (console videogames) and fifth (handheld videogames) most popular device with male children using handheld videogames significantly more than the female children. Although the majority of gaming equipment is not designed for young children but for an older target audience, once a game system enters into a household, children also use it (Bryant et al., 2010). Many of the devices that surround the younger children in society are actually not intended for their use due to the smaller hand size.

Mobile electronic device use mainly incorporates fine motor skills in its operation and play, which is evident from the intricate finger movement required in its operation. The use of these devices is expected to have revealed better fine motor dexterity scores, however this was not seen in children in this study. Both male and female children had consistently weaker dexterity scores than the standardised research scores to which they were compared (Smith \& Hong, 2000; Wang et al., 2011). It is however important to note that the comparative scores were not obtained from a SA population. Dexterity ranged between one and three seconds slower for the dominant hand, and between one 
and two seconds for the non-dominant hand. The fine motor dexterity scores of the NHPT in this study indicated the male children scored consistently slower in completion times as compared to the female children, on both the dominant and non-dominant hand. This is consistent with Smith \& Hong's (2000) study, where females displayed superior dexterity from the age of five to eight years for both the dominant and non-dominant hand. Taking into consideration the relatively slow dexterity scores, it is evident that mobile devices usage does not guarantee improved dexterity in children.

Improved handwriting dexterity is closely linked to improved handwriting performance as fine motor dexterity is an important performance component in fluent handwriting (Henderson \& Pehoski, 2006). Volman, Schendal \& Jongmans' (2006) study on handwriting in second and third grade children, with and without handwriting problems concluded that one of the underlying factors that impact the quality of handwriting is fine motor coordination. In this study, relatively low fine motor dexterity scores had been observed, with low speed and size scores in the female children's handwriting assessment. Although the handwriting scores were positively correlated to improved handwriting dexterity consistent with Cornhill and Case-Smith (1996) study, the dexterity scores were below average for $74 \%$ of the children in this study.

The MHA provided a comprehensive evaluation of handwriting for the children participating in this study and provided information regarding the speed, legibility, alignment, size, spacing, form and observations on the handwriting performance. The mean total handwriting scores of the 34 children in this study scored in the "performance like peers" range with the male children scoring higher than the female children. The speed of the female children's handwriting was scored "somewhat below peers", but displayed superior scores on the form, alignment, spacing and marginally on the legibility sub-categories of handwriting. The male children scored better in the total handwriting performance, speed and size categories. The slow work pace of the females can be a concern and can have implications within the classroom environment. The importance of fluent handwriting at age appropriate speed was reported by Roaf (1998) where $25 \%$ of the learners at secondary school level still presented with a slow writing speed. Henderson \& Pehoski (2006) argued that the lack of correct handwriting instruction and late detection of handwriting problems impacts the academic experience.

A further cause of concern was immature pencil grips observed in almost $50 \%$ of the children ( $n=16)$, which were predominantly female. The inadequate isolation and grading of the fingers affects pencil grips and directly affects fine motor dexterity. The tripod pencil grasp among other grips are important childhood developmental milestone for stimulating the correct cognitive patterns. The additionally observed handwriting faults emphasised the importance of an extensive handwriting assessment in children despite the mean total handwriting scores were considered "performance like peers".

The quality component in the sub-categories of handwriting yielded results that demonstrated slightly higher averages for legibility, alignment and spacing and significantly higher scores for form in females, with the males outperforming females on the average score for total handwriting and handwriting speed. It is postulated that the more frequent use of handheld videogames by males might have influenced the handwriting speed, although no significant correlation was found in the analysis of handheld videogames and handwriting speed.

Females scored significantly higher than the males in the form sub-category of handwriting, which was negatively correlated with their dominant hands' dexterity. Females with better hand dexterity formed their letters with more accuracy. Negative correlations were found for the size of handwriting and the dominant and non-dominant hands' dexterity. With the male children in this study, there were no significant correlations in handwriting sub-categories and dexterity, potentially due to the small sample size. Although no significant difference between genders and dominant and non-dominant hand dexterity was found, the non-dominant hands' average dexterity was very closely scored with 0.3 of a second difference between genders.

There was a positive correlation between the total time spent on electronic devices and the non-dominant hand dexterity, implying that with increase device usage, the non-dominant hands displays poorer dexterity. It is important to remember that many of the mobile devices and especially videogames incorporate bilateral hand use, where only certain electronic devices for example mobile devices incorporate predominantly the dominant hand where the index/middle finger or a pen that accompanies the device, is utilised. For mobile devices, it can be argued that the non-dominant hand is only used as a support and not for the operation, especially when handedness has been well developed as in seven to eight year olds. For this reason bilateral dexterity is under question with more frequent device usage. A weak positive correlation in total device use and total handwriting score, legibility, alignment and speed sub-categories was found and implies that electronic device use does not in essence adversely affect handwriting performance, but can aid handwriting development.

An interesting correlation exists between the handwriting speed/rate category and faulty trunk stability. A 
significant correlation existed between the popularity of tablet computers and weak trunk stability displayed by the the children. Straker et al. (2008) concluded that tablet computer use resulted in different musculoskeletal stress on the body. Tablet computer use compared to desktop computer use thus resulted in poorer posture. Additionally seating position significantly impacts young school children's object manipulation skills (Smith-Zuzovsky \& Exener, 2004). The reasons for faulty trunk stability can include multiple factors and are beyond the scope of this research, but the popularity of the tablet computer among the children may explain the weak trunk stability observed in the children. In the light of this increase in handwriting speed with more time spent on electronic devices; it was also found that children with better trunk stability displayed faster handwriting.

Handwriting development is not only crucial in the success of the child's school career, but aids in developing crucial cognitive abilities that impacts normal development on all levels. This study thus sought to determine an association between the electronic device use and handwriting and dexterity in a cohort of grade two children in SA. This pilot study is the first of its kind and provides initial data and may be valuable towards understanding the impact of these electronic devices on scholastic performance. Further research is therefore encouraged as there is little doubt that a decrease in handwriting skill will adversely impact children in our society.

\section{Acknowledgements}

The authors would like to acknowledge June McIntyre who assisted in the supervision of the first author as well as Dr T Esterhuizen for statistical support.

\section{Competing Interests Statement}

The authors declare that there are no competing or potential conflicts of interest.

\section{References}

Amundson, S. J. (2005). Prewriting and handwriting skills. In: Case-Smith, J, Occupational therapy for children (5th ed.). Missouri: Elsevier Mosby.

Bryant, J. A., Akerman, A., \& Drell, J. (2010). Diminutive subjects, design strategy, and driving scales: Preschoolers and the Nintendo DS. Game Studies. The International Journal of Computer game research, 10(1). Retrieved from https://www.researchgate.net/publication/287442707_Diminutive_Subjects_Design_Strategy_and_Driving _ Sales_Preschoolers_and_the_Nintendo_DS

Chetty, T. D., \& Bhagwanjee, A. M. (1990). Attitudes towards leisure and the desegregation of recreational facilities: A social survey. South African Journal of Sociology, 21(2). https://doi.org/10.1080/02580144.1990.10432426

Common Sense Media. (2013). Zero to Eight: Children's Media Use in America. Retrieved from https://www.commonsensemedia.org/

Connelly, V., Gee, D., \& Walsh, E. (2007). A comparison of keyboarded and handwritten compositions and the relationship with transcription speed. British Journal of Educational Psychology, 77(2), 479-492. https://doi.org/10.1348/000709906X116768

Cornhill, H., \& Case-Smith, J. (1996). Factors that relate to good and poor handwriting. American Journal of Occupational Therapy, 50, 732-739. https://doi.org/10.5014/ajot.50.9.732

Feder, K. P., \& Majnemer, A. (2007). Handwriting development, competency, and intervention. Developmental Medicine and Child Neurology, 49, 312-317. https://doi.org/10.1111/j.1469-8749.2007.00312.x

Fuentes, C. T., Mostofsky, S. H., \& Bastian, A. J. (2009). Children with autism show specific handwriting impairments. Neurology, 73, 1532-1537. https://doi.org/10.1212/WNL.0b013e3181c0d48c

Hanover Research Report. (2012). The importance of teaching handwriting in the 21stcentury. Retrieved from: http://www.zaner-bloser.com/sites/default/files/public/pdf/hw_hanover.pdf

Henderson, A., \& Pehoski, C. (2006). Hand function in the child. Foundations for remediation (2nd ed.). Mosby, Missouri: Elsevier.

Kwa-Zulu Natal Department of Education. (2006). "Literacy Learning Programmes for the Foundation Phase". Kwa-Zulu Natal Department of Education. Retrieved from http://education.gov.za/mainDocument.scp?src=docu\&xsrc=pol

Mennen, U., \& van Velze, C. (2008). The Hand Book (3rd ed.). Hatfield, Pretoria: Van Schaik Publishers.

Naidoo, P., Engelbrecht, A., Lewis, S., \& Kekana, B. (2009). Visual-motor integration (VMI) - a predictor for 
handwriting in Grade 0 children. South African Journal of Occupational therapy, 39(2), 18-21.

Reisman, J. E. (1999). Minnesota Handwriting Assessment. San Antonio, TX: Psychological Corporation.

Roaf, C. (1998). Slow hand: A secondary school survey of handwriting speed and legibility. Support for Learning, 13(1), 39-42. http://doi.org/10.111/1467-9604.00053

Smith, Y. A., \& Hong, E. (2000). Normative and validation studies of the Nine-hole Peg Test with children. Perceptual and motor skills, 90(3), 823-843. https://doi.org/10.2466/pms.2000.90.3.823

Smith-Zuzovsky, N., \& Exner, C. E. (2004). The effect of seated positioning quality on typical 6- and 7-year-old children's object manipulation skills. American Journal of Occupational Therapy, 58(4), 380-388. https://doi.org/10.5014/ajot.58.4.380

Straker, L. M., Coleman, J., Skoss, R., Maslen, B. A., Burgess-Limerick, R., \& Pollock, C. M. (2008). A comparison of posture and muscle activity during tablet computer, desktop computer and paper use by young children. Ergonomics, 51(4), 540-555. https://doi.org/10.1080/00140130701711000

Tseng, M. H., \& Chow, S.M.K. (2000). Perceptual-motor function of school-age children with slow handwriting speed. American Journal of Occupational Therapy, 54, 83-88. https://doi.org/10.5014/ajot.54.1.83

Unicef. (2012). South African mobile generation: Study on South African young people on mobiles. Retrieved from: http://www.unicef.org/southafrica/SAF_resources_mobilegeneration.pdf

Van Hartingsveldt, M. J., De Groot, I. J. M., Aarts, P. B. M., \& Nijhuis-van der Sanden, M. W. G.. (2011). Standardized tests of handwriting readiness: a systematic review of the literature. Developmental Medicine and Child Neurology, 53, 506-515. https://doi.org/10.1111/j.1469-8749.2010.03895.x

Volman, M. J. M., van Schendal, B. M., \& Jongmans, M. J. (2006). Handwriting difficulties in primary school children: A search for underlying mechanisms. American Journal of Occupational Therapy, 60(4), 451-460. https://doi.org/10.5014/ajot.60.4.451

Wang, Y. C., Magasi, S. R., Bohannon, R. W., Reuben, D. B., McCreath, H. E., Bubela, D. J., Gershon, R. C., \& Rymer, W. Z. (2011). Assessing dexterity function: a comparison of two alternatives for the NIH Toolbox. Journal of Hand Therapy, 24(4), 313-321. https://doi.org/10.1016/j.jht.2011.05.001

Wartella, E. A. \& Jennings, N. (2000). Children and computers: New technology. Old concerns. The future of children. 31-43. https://doi.org/10.2307/1602688

Wike, R., \& Oates, R. (2014). Emerging nations embrace internet, mobile technology: cell phones nearly ubiquitous in many countries. Pew Research Center, Washington DC. Retrieved from http://www.pewglobal.org/2014/02/13/emerging-nations-embrace-internet-mobile-technology

Zarghom S., Di Fonzo D., \& Leung F. (2013). Does socioeconomic status affect patients' ease of use of a touch-screen (iPad) patient survey? Interactive Journal of Medical research, 2(1). https://doi.org/10.2196/ijmr.2314

\section{Copyrights}

Copyright for this article is retained by the author(s), with first publication rights granted to the journal.

This is an open-access article distributed under the terms and conditions of the Creative Commons Attribution license (http://creativecommons.org/licenses/by/4.0/). 